\title{
Development and Evaluation of Innovative Recycling Intervention Program Using the Health Belief Model (HBM)
}

\author{
Israel G. Msengi \\ Health and Kinesiology Department, Lamar University, Beaumont, TX, USA \\ Email: igmsengi@my.lamar.edu
}

How to cite this paper: Msengi, I.G. (2019) Development and Evaluation of Innovative Recycling Intervention Program Using the Health Belief Model (HBM). Open Journal of Preventive Medicine, 9, 29-41. https://doi.org/10.4236/ojpm.2019.94004

Received: February 1, 2019

Accepted: April 27, 2019

Published: April 30, 2019

Copyright (c) 2019 by author(s) and Scientific Research Publishing Inc. This work is licensed under the Creative Commons Attribution International License (CC BY 4.0).

http://creativecommons.org/licenses/by/4.0/ (c) () Open Access

\begin{abstract}
The purpose of this study was to assess the effectiveness of interventions based on health promotion theories in changing the recycling behavior of the targeted population. The study focused on the development and evaluation of innovative recycling education programs that address energy recovery, recycling, and waste management. The study applied Health Belief Model-(HBM) as an approach to motivate recycling behaviors and to evaluate the impact of the applied approaches on recycling set-out rates and participation. A total of 102 households from a Midwestern city participated in this study. The study was conducted over a period of six months. A Likert scale questionnaire was used to collect data on recycling and environmental knowledge, skills, behavior, and attitudes. The other set of data was the weight of recyclables that was obtained at each participant's curb four times over the six months period of interventions. Results indicated a significant increase in average set out rates of recyclables among HBM participants $(21.34 \mathrm{lbs}$. pre-test to $59.3 \mathrm{lbs}$. post-test). It was concluded that HBM educational approaches can be effective in motivating recycling. This study signifies the need for renewed effort in motivating individuals, households or businesses to recycle. Not every community or city significantly participates in recycling. Innovative strategies as well the application of approaches in the theories of behavioral change can positively influence recycling and overall waste reduction behaviors.
\end{abstract}

\section{Keywords}

Recycling, Environmental Health, Health Belief Model (HBM), Theory, Health Behavior

\section{Introduction}

Recycling today may seem like a by-gone topic but it actually still very relevant. 
A great number of people still do not participate in regular recycling [1] [2]. For example, of the 4.38 pounds that an American produces only 1.5 pounds is recycled [3]. This is one arena of environmental behavior that has received a lot of attention in recent years but the pace in which people are adopting the recycling behavior is very slow [4] [5]. Although recycling is not a new phenomenon, today over $75 \%$ of solid waste by weight and $90 \%$ by volume are product packaging related [3] [6]. Globally, reports indicate there is a steady increase in Municipal Solid Waste (MSW) globally [7]. For instance, it is estimated that 3 billion tons of MSW were generated by residents in 2012 where each person generates 1.2 kilograms or 2.65 pounds per day. The waste generation trajectory will more than two-times outpace population growth by 2050 [8].

\subsection{Literature Review}

In 1999, one American generated approximately 4.6 pounds of solid waste materials each day, twice the daily amount of waste generated by an individual (2.7 pounds) in 1960 [9]. In 2003 the net per capita discard rate after recycling and composting was 3.09 pounds per person per day, a little below the 3.14 pounds per person per day in 2002. In 2008, the US generated 250 million tons of solid waste and only 83 million tons (33.2\%) were recycled. In 2012 an individual still generated nearly the same amount of waste $(4.38 \mathrm{lbs})$ per day and recycled only 1.5 pounds [3]. The US EPA MSW report shows that MSW generation rate has remained relatively constant since the 1990s at 4.4 pounds per individual per day. Americans generated 251 million tons of trash in 2012 compared to 236.2 million tons in 2003 and 250.4 in 2010. Of the 251 million tons generated in 2012, 55\% to $65 \%$ of total MSW came from residential sources including apartment houses, and $35 \%$ to $45 \%$ from school and commercial locations such as hospitals and businesses [3]. This estimate does not include industrial, hazardous, or construction waste [3]. In the same year (2012), Americans recovered over 65 million tons of MSW through recycling and nearly 29 million tons through composting. The Americans recycling rate in 2012 was 34.5\% compared to $31.4 \%$ in 2005 and $34.0 \%$ in 2008 [3]. The total MSW generated in 2015 was 262.4 million tons. Of those, nearly 52.5\% went to landfills, 25.8 recycled and 8.9\% composted [3]. Paper and paperboard was the largest part of the MSW (25.9\%) followed by food (15.1\%) yard trimmings (13.2\%) and plastics (13.1\%). A survey among Americans in 2017 on recycling indicated more than half of participants had curbside pick-up of recyclable materials [9]. According to the Pew Research Center FACTANK report on perceptions and realities of recycling, $28 \%$ of Americans stated their local community's social norms strongly encourage recycling and re-use, while $22 \%$ stated they do not. Fifty percent reported their communities were in neither side regarding recycling [10]. Nation-wide, there are approximately 9800 curbside recycling programs somewhat up from 9700 curbside programs in 2001 and 8660 in 2006 [10]. However, the US EPA states that household waste remains a constant concern because trends 
indicate that the overall tonnage we create continues to increase [3] [9].

It is obvious that households possess the key to sustainable management of solid waste. Waste minimization, reuse, and recycling rates vary substantially among individual households for various reasons, which include; personal variables (attitude toward the environment, knowledge, demographic variable, and personality) or situational issues (removal of recycling barriers, prompting, obtaining commitment to recycle, use of social norms, rewards, and providing feedback) [11]. Hence, only changes in individual attitudes, beliefs, norms towards the environment, and the consequential shift in personal behavior, will have the lasting and significant impact on the environment that is badly needed [12].

\subsection{Promoting Recycling by Using Health Education/Promotion Theoretical Approaches}

\subsubsection{Theories and Models}

Health promotion and health education theories and conceptual models can be very useful in guiding interventions that seek to elicit behavior changes (including recycling behavior) to minimize the impact of human activities on environmental systems [13]. Nonetheless, these theories and conceptual models that are regularly applied to direct health promotion and health education interventions are hardly ever employed to environmental health education issues, including recycling [13]. This indicates that health promotion has been largely absent from the environmental health arena [14]. Thus, successful implementation of interventions in environmental health promotion, including recycling, requires an appreciation of what the field of health promotion has to offer [15]. This study utilized theoretical approaches of health education/promotion while using similar content messages, namely: Intrapersonal (Health Belief Model-HBM) approach.

\subsubsection{Health Belief Model (Intrapersonal Approach)}

Intrapersonal-level theories and models are the most often utilized when planning interventions to increase recycling participation, even if recycling coordinators and educators do not associate them, theoretically, with health promotion models. The HBM is one of the theories of individual behavior (Intrapersonal) that focuses mainly on the knowledge, attitude and behavior of an individual [16]. Being one of the most utilized conceptual frameworks for understanding health behaviors, the HBM has been used with great success for nearly half a century to promote positive health behaviors in order to prevent negative health consequences [17]. Originating from psychological expectancy-value models and behavioral theories, the HBM asserts that behavior depends mainly on two variables: 1) the values placed by an individual on a particular goal; and 2) an individual's estimate of the likelihood that a given action will achieve that goal [17]. In the context of health behavior, the HBM targets an individual's perceptions of the threats posed by a health problem, the benefits of avoiding the threat, and 
factors influencing the decision to act [13] [18].

The key concepts of the HBM are: perceived susceptibility, perceived severity, perceived benefits, perceived barriers, cues to action, and self-efficacy [13] [18]. Based on the review of all HBM studies published between 1974 and 1984, perceived barriers, perceived benefits, and perceived susceptibility were identified as significant variables in predicting and explaining health-related behaviors [17]. However, most recent studies indicate self-efficacy as the strongest predictor of health-related behavior [19] [20].

The purpose of this study was to assess the effectiveness of interventions based on health promotion theories in changing the recycling behavior of the targeted population. The study focused on the development and evaluation of innovative recycling education programs that address energy recovery, recycling, and waste management. The intervention program design was based upon proven behavior modification strategies utilized in health promotion and health education that are further modified for the delivery of recycling education with the goal of more effective recycling education campaigns. A theory driven approach to educational program implementation and evaluation which draws on health education/promotion theory and practice (HBM) was modified and applied to this area of environmental health education in order to motivate recycling. This quasi-experimental study applied selected health promotion theories and models in the case the HBM as an approach to motivate recycling behaviors [21] [22]. The impact of the applied HBM approaches on recycling set out rates and participation was evaluated. The outcome of the research program was measured and evaluated on a short- and long-term basis (two and six months) with the goal of realizing a $10-15 \%$ shift in recycling participation.

\section{Methodology}

This was conducted among residents in a Midwestern State city where a total of 102 households participated in the study. The study utilized both quantitative and qualitative approaches (mixed method) during the intervention process [23] [24]. The combination of mixed methods was applied mainly during the intervention and community leader informative meetings (school principals, Scout group coordinators, and church ministers).

\subsection{Interventions}

After obtain research approval from the Institutional Review Board (IRB), households to participate in the study were identified. This residential area was one that yielded the lowest recyclable setouts. The intervention approach at the intrapersonal level adopted from HBM was applied in the intervention process. The intrapersonal approach focused on individuals by influencing their knowledge values, beliefs, and attitudes about recycling through innovative provision of educational messages. This innovative educational approach also empowered people to take control of their recycling behavior. Attention was paid to the de- 
sign of the educational materials and to their delivery with the intention of catching people's attention. The appeal of the materials delivered and the persistence of the intervention approach were considered key to getting people interested in partaking in the recycling process and programs. Education materials such as brochures, posters, and fliers were used. This was accomplished by both house-to-house visits and mailing of additional useful materials. In addition, follow-up telephone calls, feedback on recycling progress, and direct mailing were used to remind people about recycling. The following combinations of educational intervention strategies were applied.

\subsubsection{Modeling Strategy}

Educational messages were prepared and communicated to participants creatively by applying theoretical approaches of behavioral change (the HBM). Messages disseminated recognized barriers to recycling but at the same time provided a way to overcome the barrier. For example a flier and brochure provided scenarios and solutions for people who find they do not have time to sort materials or lack time to shop for products with less packaging. Demonstrative messages that portrayed the benefits of recycling and stressed that "it is not a hard to do thing" were used to counter time constraint self-talk as a reason not to participate in recycling activities. Messages designed were simple, easy to understand, quick to read, and those that could fit audiences of all socio-economic status.

\subsubsection{Feedback Providing Strategy}

This innovative educational information delivery approach incorporated messages that provided feedback on how much people were recycling in pounds and whether they needed improvement. This information tied relevant facts directly with the individual's recycling behaviors. This strategy was applied to participants where communication was initiated directly with an individual participant. The feedback information contained the amount, in pounds, of recyclable that each participant off-set after a specific intervention phase.

\subsubsection{Reminders and Prompts Approach}

This was another way to motivate recycling participation. The messages in this approach were specifically targeted to overcoming behaviors or barriers such as laziness and forgetfulness. These reminders were timely and specific to the current recycling situation. Telephone messages, mail cards, text messages, and emails were some of the approaches applied to remind participants to recycle.

\subsubsection{The Pledge to Recycle Approach}

This method was designed to increase public commitment and encourage people to commit via a signed pledge. This pledge sought to encourage people to take action and continue in recycling.

\subsection{Instruments and Data Collection}

The Knowledge, Skills, and Ability (KSA) scale was used to both establish a base- 
line and to measure changes of knowledge, awareness, attitude, and behaviors toward recycling following educational interventions. The KSA scale which uses a Likert Scale was adopted from Barr (2002) and modified in order to fit the needs of this study [25]. Barr (2002) designed the scale and utilized it to study knowledge, values, attitudes, and behaviors toward recycling household waste in Exeter, Devon UK. The scale measured environmental attitudes, knowledge, values, and behaviors affecting recycling participation. The modified scale was tested for internal reliability in each of its subscales. A Cronbach's Alpha reliability test for internal consistency of subscale items (recycling activity, knowledge, attitude, and behavior) was calculated using JMP8.SAS Institute [26]. The Cronbach's Alpha reliability test was chosen as the best approach due to the fact that it tends to provide a high estimate of reliability. An Alpha coefficient score of $\alpha=0.7$ or better suggests a satisfactory degree of reliability [27]. For highly correlated items the coefficient can approach $\alpha=1.0$. The Cronbach's Alpha for activity subscale was $\alpha=0.870$; knowledge subscale $\alpha=0.630$; attitude subscale $\alpha=$ 0.760 ; skills subscale $\alpha=0.949$; and behavior subscale $\alpha=0.833$. The data sets were for the actual recyclable weights that were collected from the curb. One set of weight data was gathered before the educational interventions, while two other weight data sets were gathered during the intervention period, and the final weight data set was collected after interventions. These data sets helped to evaluate the progress of the effectiveness of interventions both in the short and long-term.

\subsection{Data Processing and Analysis}

Data was coded and entered into the JMP8; SAS Institute statistical package. Various quantitative statistical approaches in analyzing data for this study were employed to determine the impact of interventions on recycling activity, knowledge, behavior, skills, and attitude of participants. The following statistical tests were performed: univariate statistics such as descriptive statistics. Descriptive statistics were performed to generate percentages, frequencies, means, and case and group summaries. Descriptive statistics provided a description of the samples or distribution characteristics of the variables in recycling activity, knowledge, behavior, skills, attitude, and waste management strategies.

\section{Results}

One-hundred-and-two households participated in the project were the HBM model was applied. Twenty nine percent of participants had BA or BS degree, $27.5 \%$ had a GED diploma, and $26.8 \%$ had a graduate degree.

\subsection{Recycled Waste}

Before interventions residents in the study area were surveyed to find out which materials they were likely recycle. Figure 1 indicates percentages of individual materials they were likely to recycle in the study area. These included: glass 


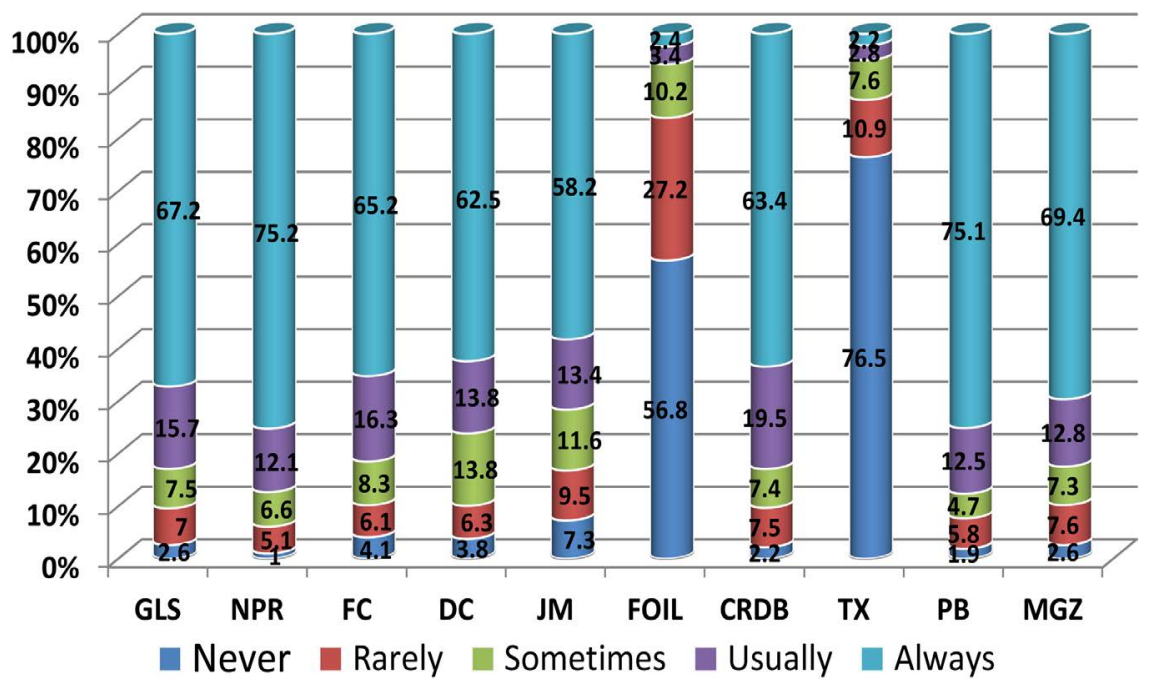

Figure 1. Overall percentages of recycled items and setout percentages before intervention.

(GLS; 67\%), newspaper (NPR; 75.2\%), food cans (FC; 65.2\%), drink cans (DC; 73.03\%), and plastic bottles (PB; 75.1\%). Other solid wastes recycled were junk mail (JM; 58.2\%), cardboard (CRDB; 63.4\%), and magazines (MGZ; 69.4\%). Foils (56.8\%) and textiles (TX; 76.5\%) were rarely or never recycled.

\subsection{Recycling Rate before and during Interventions}

Figure 2 shows the average amount of solid waste setouts in pounds per household before and after intervention in a biweekly basis. A significant increase in recyclable output was observed after interventions.

As indicated in Figure 2, there was a steady increase in recyclable set-out rates from baseline to the final intervention. Under the HBM intervention approach participants responded to educational interventions by setting out more recyclables (59.3 lbs.) biweekly by the end of the intervention period. These innovative educational interventions were delivered constantly and were consistently on recycling message.

\subsection{Recycling Activity}

In responding a questionnaire item related to how participants managed recyclable before interventions a Likert scale of $(1=$ never, $2=$ rarely, $3=$ sometimes, 4 = usually, 5 = always) for subscale questionnaire items about recycling activity and waste management was used. Participants reported they never or rarely bought items with little packaging $(m=1.8, s d=0.990)$, used their own fabric shopping bags rather than the ones provided by the store $(m=1.7, s d=0.802)$, looked for easily reusable packaging $(m=1.9, s d=1.215)$, and/or reused papers $(m=1.9, s d=0.956)$.

However, the post-test results indicated a change in participants' waste management behaviors. See Table 1. 


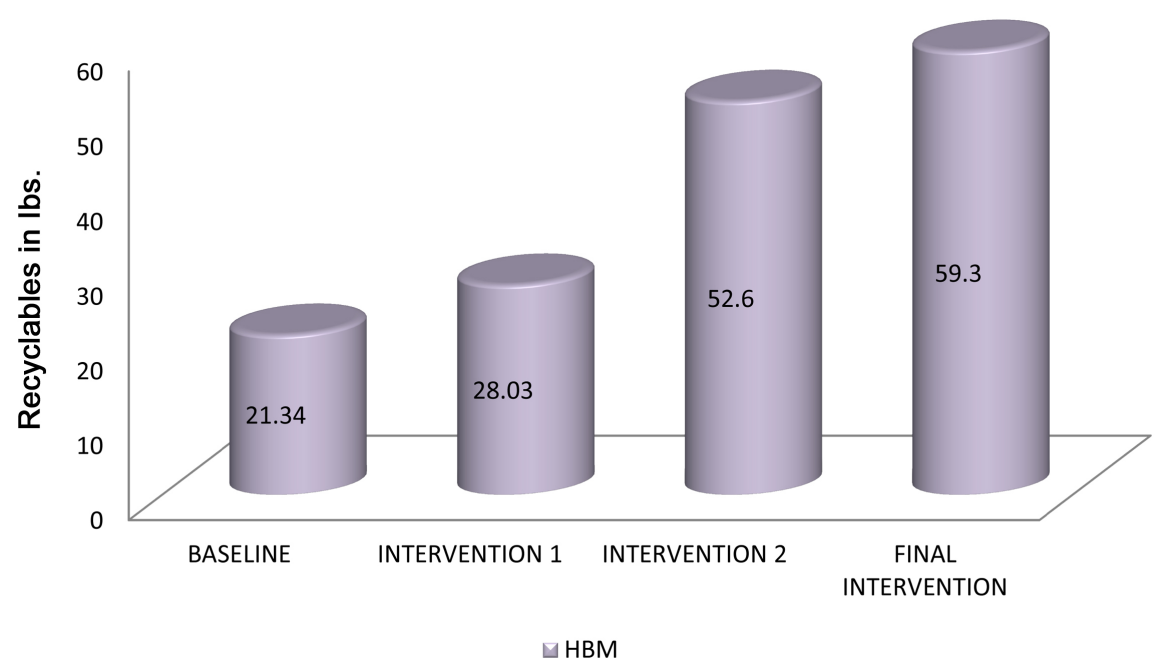

Figure 2. Biweekly recyclable outset rate in pounds per individual in various intervention phases.

Table 1. Pre- and post-test mean responses for HBM group in recycling activity subscale items.

\begin{tabular}{ccccc}
\hline Sub-scale & \multicolumn{3}{c}{ HBM } \\
\hline Recycling Activity \& Waste Control & \multicolumn{2}{c}{ Pre-test } & \multicolumn{2}{c}{ Post-test } \\
\cline { 2 - 6 } & $m$ & $s d$ & $m$ & $s d$ \\
\hline Buy items with little packaging & 1.8 & 0.990 & 4.0 & 1.144 \\
Using my own bag when shopping & 1.7 & 0.802 & 3.5 & 1.229 \\
Look for reusable packaging & 1.9 & 1.215 & 3.8 & 1.195 \\
Buy vegetables \& fruits lose & 2.6 & 0.775 & 4.6 & 0.745 \\
Buy reusable products & 2.5 & 0.783 & 4.6 & 0.762 \\
Repair than buy new items & 2.6 & 0.937 & 4.7 & 0.922 \\
Reuse paper & 1.9 & 0.956 & 4.2 & 1.024 \\
Reuse glass bottles \& jars & 1.4 & 1.462 & 4.2 & 1.277 \\
Wash and reuse dishcloths & 2.9 & 0.854 & 4.7 & 0.924 \\
Reuse plastic containers & 2.9 & 1.238 & 4.3 & 1.123 \\
\hline
\end{tabular}

Note. $1=$ never, 2 = rarely, $3=$ sometimes, $4=$ usually, $5=$ always.

\subsection{Recycling Knowledge}

Questions in the knowledge subscale tested participants' knowledge on issues related to the environment (Ev), solid waste (SW), Sustainable Development (SD), and Local Agenda 21(LA). Responses were "True" and "False". Figure 3 represents the percentage of correct answers to knowledge questions before and after interventions for the participants where HBM intervention method was applied. During post-test, participants improved their scores of correct answers. Under the HBM intervention approach educational materials such as brochures, posters, and fliers were consistently delivery to residents that participated in the 


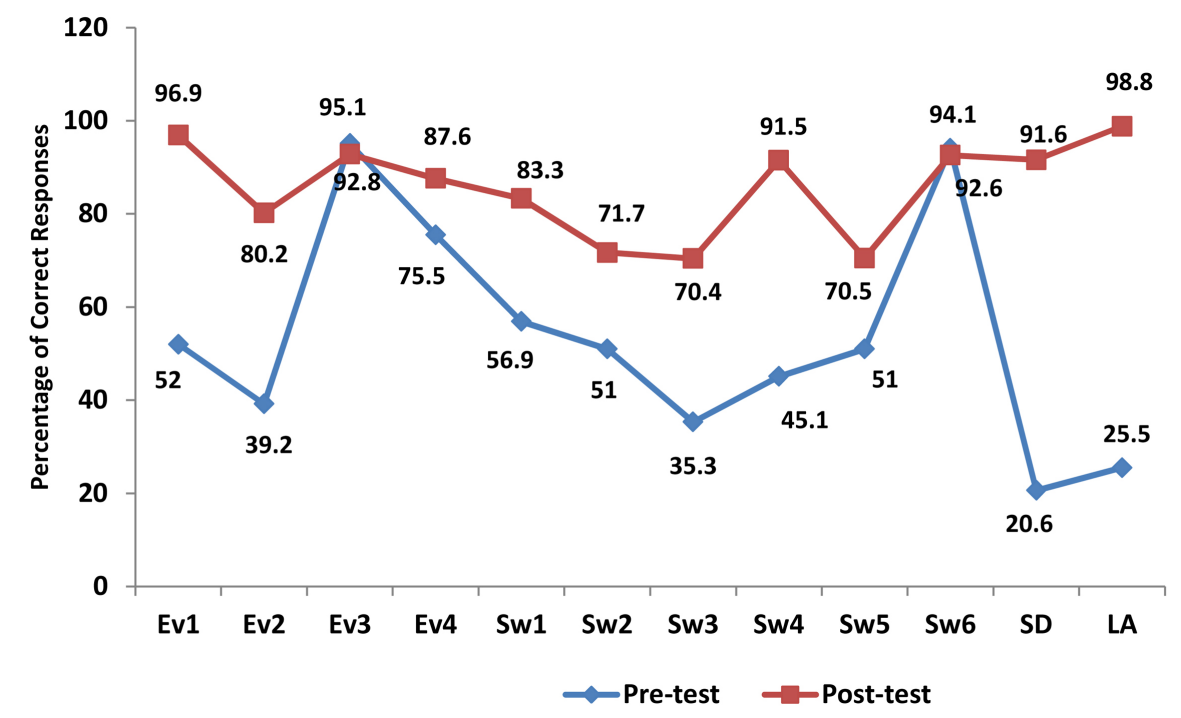

Figure 3. Recycling knowledge before and after intervention. Note. Ev1 = Global warming is a growing health and environmental concern today. Ev2 = Warming in the atmosphere is due mainly to increased human produced carbon dioxide. Ev3 = Recycling is central to controlling the depletion of natural resources. Ev4 = Road transportation produces few harmful emissions into the atmosphere ${ }^{\star}$. SW1 = One third of total household water supply is used to flush toilets. SW2 $=$ Households produce a minority of the waste handled by the city*. SW3 = Each average household produces $32 \mathrm{lbs}$. of waste every week. SW4 = Under one-tenth of household waste is recycled. SW5 = Sending waste to a landfill site is only a small part of the way waste is disposed of ${ }^{\star}$. SW6 $=$ Landfill sites are running out of space for more waste. $\mathrm{SD}=$ Have you heard of "Sustainable Development". LA = Have you heard of "Local Agenda 21". ${ }^{*}$ indicates participants would receive a point if they responded "NO" to the item.

study. These materials were considered key in increased knowledge as well as motivating them in partaking in the recycling process.

\subsection{Change in Attitude and Value for Environment}

To determine attitude and value for the environment, participants in the study were asked questions ( $1=$ Strongly Agree and $5=$ Strongly Disagree $)$ about their attitude and concerns towards natural resources, and waste management issues. Participants were asked about policy development (PD), their attitude towards natural resources (NR), personal concerns (PC), and waste issues (W). Participants indicated they were neutral both during pre-test and post-test regarding a statement suggesting the environment was often forgotten when decisions are made (PD) $(m=3.2, s d=0.975)$, or humans should not develop any resources or land, in order to protect the natural environment (NR4) $(m=3.2, s d=1.209)$. During pre-test, participants disagreed or strongly disagreed that the problem of waste posed a threat to their well-being and health $(m=3.7, s d=1.317)$. However, after the interventions, a majority of participants reported they agreed or strongly agreed that the problem of waste posed a threat to their well-being and health $(m=1.6, s d=0.776)$. In addition, during pre-test participants reported they agreed or strongly agreed $(m=1.8, \mathrm{sd}=0.786)$ that their personal 
well-being was not affected by problems of waste disposal. The post-intervention responses, however, indicated they disagreed or strongly disagreed $(m=4.4, s d=$ $1.203)$ that their personal well-being was not affected by the problem of waste disposal.

\subsection{Waste Minimization Skills}

In terms of Waste Minimization Skills or Willingness to Reduce Waste subscale ( 1 = Very Willing, 5 = Very Unwilling), participants were asked about whether or not they were willing to reduce waste. A majority of respondents both during pre-test and post-test reported they were neutral or somehow unwilling to adopt waste minimization skills (Ms) such as buying fewer disposable items $(m=3.4$, $s d=1.225)$, looking for products with less wrappings $(m=3.0, s d=1.208)$ and/or taking old plastic bags for shopping rather than getting new ones at the store $(\mathrm{m}=3.3, s d=1.116)$. However, the post-test responses indicated a majority of them were willing or strongly willing to wash and reuse certain items before disposing of them $(m=1.5, s d=0.604)$.

\subsection{Recycling Behavior}

The behavior subscale sought to obtain responses regarding participants' recycling behavior in order to determine participants' intentions reflecting the need to help the environment ( $1=$ Strongly Agree, $5=$ Strongly Disagree). The pre-test responses indicated participants were neutral in reporting whether their behavior to recycle was influenced by seeing neighbors and friends reuse and recycle things ( $m=3.1, s d=0.820$ ) or whether they needed financial incentives in order to recycle $(m=3.3, s d=1.235)$. However, during post-test participants reported they were motivated to recycle when they saw others recycle $(m=1.3, s d=0.756)$. Participants also reported they felt guilty for not recycling $(m=2.1, s d=0.887)$. Other responses that indicated behavioral change after interventions were that participants agreed or strongly agreed that they were very concerned with waste issues or problems $(m=1.6, s d=1.078)$ and realized that participating in recycling and managing waste was simple $(m=1.6, s d=0.963)$.

\section{Conclusions}

The findings reported in this study demonstrate the way health promotion and education theories and models can be applied in environmental health practice and particularly in encouraging recycling behavior and in assessing the interventions' impacts on recycling behavior, attitude, skills, knowledge, and waste minimization. Overall, from this study, it can be stated that: 1) HBM educational intervention approaches are efficient if, largely, they are not too demanding of participants; i.e. if they are relatively simple and low cost to the individual's behaviors. 2) Activities such as recycling papers, taking recyclables to the curb, adjusting shopping habits, reusing items, and repairing items can easily be adopted when appropriate intervention strategies are utilized. Change of participants' 
norms, attitudes, and beliefs directly affects behaviors, which in turn may eventually change community policies. 3) Education can change people's values. Environmentally-related values and beliefs, such as recycling, once adopted may be lasting. Hence educational efforts that work along with peoples' ethics and values can ultimately change people's attitude and behaviors. 4) It is essential to design educational materials and messages that can effectively communicate the intended factual messages while modeling attitude and behavior shifts of participants.

However, making information available to participants does not necessarily guarantee that the information will be used. It is essential to use trusted information sources so that people can consider incorporating it in a new behavioral repertoire. In this study participants indicated that the information sources they trusted the most included the city newsletter, utility newsletters, TV, magazine, word of mouth from friends, Internet, and neighborhood associations or clubs. Education interventions are more effective when combined with other intervention strategies, as expressed in the open comments of participants (i.e., doing more than just educating). In the case of recycling participants suggested improving services such as changing collection frequency from biweekly to every week. Some participants noted, "Recycling would be easier if it was collected weekly - we us 2+ bins each recycle day." Similarly, other participants stated, "I would like pick-up to be weekly so I wouldn't forget." Another participant said, "I wish that our city's curbside recycling program would allow more things to be recycled, such as plastic bags, plastic from packing, and paint.”

\section{Recommendation}

Findings from this study render the following recommendations:

1) Further study should be conducted to explore how other health promotion theories can be used in similar recycling investigations. In this study HBM educational and intervention strategies were applied not the theory's constructs per se. Findings indicated on an overall these theoretical approaches are effective in increasing recycling participation and increasing recycling skills, waste reduction, attitude, behavioral change, and commitment to protecting the environment.

2) Service improvement is another essential element that can encourage or promote a particular behavior, such as recycling. The majority (73\%) of participants expressed dissatisfaction with collection days, small bins, and a lack of diversification of the materials collected. Participants indicated that they preferred weekly collection rather than the current biweekly collection. To provide only a few of these comments, participants stated: "I wish pick up was weekly." A similar statement of dissatisfaction was "I dislike it when the recycling pick-ups were reduced from weekly to bi-weekly. Now there is talk of reducing it to monthly. While I do not find it inconvenient to separate recyclables by type, many people say they don't recycle because it's too complicated. When I visit Phoenix, AZ 
they throw everything into a recycling container randomly and employees of the recycling firms sort it. I would like to see disposal of hazardous materials made easier. Rather than dispose of them unsafely... The most recent proposal I've heard is that the city is considering eliminating the pick-up of recyclables and requiring residents to drive everything to a drop-off site. I can't do this; I think it's a very disturbing proposal." So it is essential to improve services, and also to listen to concerns that clients have.

3) Knowledge about the community/local values, norms, and behaviors is imperative. There is a need for interventionists to be very familiar with the culture, norms, and behaviors of the community in which interventions are taking part. Such knowledge is essential for tailoring interventions that can bring about behavioral change.

\section{Conflicts of Interest}

The author declares no conflicts of interest regarding the publication of this paper.

\section{References}

[1] Ackerman, F. (1997) Why Do We Recycle? Markets, Values, and Public Policy. Island Press, Washington DC.

[2] Achapan, I. (2012) The Reason behind Lack of Household Recycling Participation. A Bangkok Metropolis Case Study. Global Journal of Human Social Science Arts and Humanities, 12, 79-82.

[3] U.S. Environmental Protection Agency (US EPA) (2015) Municipal Solid Waste Generation, Recycling, and Disposal in the United States: Facts and Figures for 2012.

https://www.epa.gov/facts-and-figures-about-materials-waste-and-recycling/studies -summary-tables-and-data-related

[4] Gamba, R. and Oskamp, S. (1994) Factors Influencing Community Residents' Participation in Commingled Curbside Recycling Programs. Environmental and Behavior, 26, 587-612. https://doi.org/10.1177/0013916594265001

[5] Hershkowitz, A. (1998) In Defense of Recycling. Social Research, 65, 141-218.

[6] White House Task Force on Recycling (2000) Recycling for the Future. http://www.grrn.org/assets/pdfs/wasting/WRUS.pdf

[7] Hoornweg, D. and Bhada-Tata, P. (2012) What a Waste: A Global Review of Solid Waste Management. Urban Development Series; Knowledge Papers No. 15. World Bank, Washington DC. https://openknowledge.worldbank.org/handle/10986/17388

[8] Kaza, S., Yao, L.C., Bhada-Tata, P. and Van Woerden, F. (2018) What a Waste 2.0: A Global Snapshot of Solid Waste Management to 2050. Urban Development. World Bank, Washington DC. https://doi.org/10.1596/978-1-4648-1329-0 https://openknowledge.worldbank.org/handle/10986/30317

[9] U.S. Environmental Protection Agency (US EPA) Frequent Questions on Recycling. https://www.epa.gov/recycle/frequent-questions-recycling

[10] Schultz, P.W. (2002) Knowledge, Information, and Household Recycling: Examining the Knowledge-Deficit Model of Behavior Change. In: Dietz, T. and Stern, P.C., Eds., New Tools for Environmental Protection: Education, Information and Volun- 
tary Measures, National Academy Press, Washington DC, 67-82.

[11] Pew Research Center (2016) Perceptions and Realities of Recycling Vary Widely from Place to Place.

http://www.pewresearch.org/fact-tank/2016/10/07/perceptions-and-realities-of-recy cling-vary-widely-from-place-to-place

[12] Oskamp, S.R., Burkhardt, P.W., Schultz, S.H., Hurin, S. and Zelezny, L. (1998) Predicting Three Dimensions of Residential Curbside Recycling: An Observational Study. Journal of Environmental Education, 29, 37-42. https://doi.org/10.1080/00958969809599111

[13] Parker, E.A., Baldwin, G.T., Israel, B. and Salinas, M.A. (2004) Application of Health Promotion Theories and Models for Environmental Health. Health Education and Behavior, 31, 491-509. https://doi.org/10.1177/1090198104265601

[14] Howze, E.H., Baldwin, G.T. and Kegler, M.C. (2004) Environmental Health Promotion: Bridging Traditional Environmental Health and Health Promotion. Health Education and Behavior, 31, 429-440. https://doi.org/10.1177/1090198104265591

[15] Kegler, M.C. and Miner, K. (2004) Environmental Health Promotion Interventions: Considerations for Preparation and Practice. Health Education and Behavior, 31, 510-525. https://doi.org/10.1177/1090198104265602

[16] Rosenstock, I.M. (1974) Historical Origins of the Health Belied Model. Health Education Monogram, 2, 328-335. https://doi.org/10.1177/109019817400200403

[17] Janz, N.K. and Becker, M.H. (1984) The Health Belief Model: A Decade Later. Health Education Quarterly, 11, 1-47. https://doi.org/10.1177/109019818401100101

[18] Glanz, K., Rimer, B.K. and Lewis, F.M. (2008) Health Behavior and Education: Theory, Research, and Practice. 4rd Edition, Jossey-Bass, San Francisco.

[19] Gillbrand, R. and Stevenson, J. (2006) The Extended Health Belief Model Applied to the Experience of Diabetes in Young People. British Journal of Health Psychology, 11, 155-169. https://doi.org/10.1348/135910705X39485

[20] Lin, P., Simoni, J. and Zemon, V. (2005) The Health Belief Model, Sexual Behaviors, and HIV Risk among Taiwanese Immigrants. AIDS Education and Prevention, 17, 469-483. https://doi.org/10.1521/aeap.2005.17.5.469

[21] Campbell, D.T. and Stanley, J.C. (1973) Experimental and Quasi-Experimental Designs for Research. Rand McNally College Publishing Company, Chicago.

[22] Shadish, W.R., Cook, T.D. and Campbell, D.T. (2002) Experimental and Quasi-Experimental Designs for Generalized Causal Inferences. Houghton Mifflin Company, Boston.

[23] Creswell, J.W. (2018) Research Design: Qualitative, Quantitative, and Mixed Methods Approaches. Sage Publications, Inc., Thousand Oaks.

[24] Morgan, D.L. (1998) Practical Strategies for Combining Qualitative and Quantitative Methods: Application to Health Research. Qualitative Health Research, 8, 362-376. https://doi.org/10.1177/104973239800800307

[25] Barr, S. (2002) Household Waste in Social Perspective: Values, Attitudes, Situation and Behavior. Ashgate Publishing Ltd., Aldershot.

[26] Cronbach, L.J. (1951) Coefficient Alpha and the Internal Structure of Tests. Psychometrika, 16, 297-334. https://doi.org/10.1007/BF02310555

[27] Garson, D. (2016) Reliability Analysis. $\underline{\text { http://www.statisticalassociates.com/validityandreliability_p.pdf }}$ 